\title{
RESEARCH PAPER \\ A HOLISTIC SURVEY OF DAMPNESS IN A SIX BEDROOM RESIDENTIAL APARTMENT
}

\author{
K. Agyekum ${ }^{l}$, J. Ayarkwa ${ }^{2}$ and C. Koranteng ${ }^{3}$ \\ ${ }^{1,2}$ Department of Building Technology, KNUST, Kumasi \\ ${ }^{3}$ Department of Architecture, KNUST, Kumasi \\ E-mail of corresponding author: agyekum.kofil@gmail.com
}

\begin{abstract}
As one of the most damaging failures that occur in buildings, dampness in all its forms affects both old and modern types of buildings. As an important function, buildings should seek to prevent water penetrations and give envelop to their occupants. This study adopted a holistic approach to dampness surveying to identify and document the areas in a six bedroom residential building severely affected by dampness. A case study approach which involves a three-stage protocol of damp investigation, thus visual inspection, non-destructive tests using a moisture meter and destructive testing was used in the study to identify and document areas in the building severely affected by dampness. The results from the visual investigation showed that dampness was seen on the external and internal walls of the building and was accompanied by symptoms such as damp patches in horizontal bands, blistering of paint, surface efflorescence, stains and in some portions mould growth. A further investigation with the moisture meter showed that the problem was very pronounced in the walls located in the western orientation. Also, destructive tests revealed that the dampness in the bathrooms and kitchen were due to plumbing leakages and rain water penetration respectively. Further research on affected buildings situated in different ground conditions is recommended. This study should serve as a platform for further studies to be conducted on the building in order to trace the visible evidence back to the actual seat of the problem. In so doing, it should provide a platform for all stakeholders in the construction industry to come together to address this common but dangerous problem.
\end{abstract}

Keywords: Dampness, residential buildings, plumbing leakage, rising damp, water penetration

\section{INTRODUCTION}

Water, a substance required for the continuity of human life plays an important role in structural applications. Buildings should be constructed with materials which have the tendency to resist the effects of water through its service life (Yilmaz et al., 2010). For a building to perform this function there is the need for correct design and maintenance throughout the life of the building (Yilmaz et al., 2010). Moisture that should not be present in a building is known as dampness (Burkinshaw and Parrett, 


\section{Agyekum et al.}

2004). A building is said to have a dampness problem when the materials in the building become sufficiently damp leading to material damage or visible mold growth (Burkinshaw and Parrett, 2004).

\section{MATERIALS AND METHODS}

In a tropical region like Ghana characterized by high rainfall with relatively high and even temperatures, dampness is a very common problem among many buildings, both public and private. According to Halim et al. (2012), dampness can be defined as water penetration through the walls and certain elements of a building. Briffet (1994) defined dampness as the excessive quantity of moisture contained within building materials and components which cause adverse movements and deterioration and results in unacceptable internal environmental conditions.

Dampness in walls of buildings is inextricably linked to most building deterioration (Hollis, 2002). It also creates unsightly appearances, emanates bad odour in houses and causes permanent damage to plaster, paint and finishes (Halim and Halim, 2010; Hetreed, 2008; Burkinshaw and Parrett, 2004). Dampness is a very serious structural defect which spoils paints and interior decorations, encourages mould and rot growth, hampers aesthetics, poses a threat to the health of occupants, etc. (Mbachu, 1999). Also, dampness can lead to cosmetic problems, damage to building fabrics, structural problems and at certain instances create adverse health effects on residents of the affected building (Oxley, 2003). Preliminary investigations carried out prior to this study revealed that dampness has assumed an alarming rate in most buildings in Ghana (Agyekum et al., 2013). This paper presents a typical case of a six bedroom residential apartment suffering from the problem of dampness. The study aims at identifying the areas in the building severely affected by dampness through non-destructive and destructive testing of the affected areas.

\section{The study area}

The building is situated at Kwamo, a suburb of the Ejisu-Juaben Municipal Assembly, one of the 27 administrative and political districts in the Ashanti Region of Ghana. The municipality stretches over an area of $637.2 \mathrm{~km}^{2}$ constituting about $10 \%$ of the entire Ashanti Region and with Ejisu as its capital. The municipality is located in the Ashanti Region and provides enormous opportunity for creating an inland port for Ghana to serve the northern section of the country. It lies within latitude $1^{\circ} 15^{\prime \prime} \mathrm{N}$ and $1^{\circ} 45^{\prime \prime} \mathrm{N}$ and longitude $6^{\circ} 15^{\prime \prime} \mathrm{W}$ and $7^{\circ} 00^{\prime \prime} \mathrm{W}$ (www.ghanadistricts.com/home).

The area falls within the moist semi deciduous forest which occurs in the wet semi - equatorial climatic region of Ghana. Annual rainfall is between $125 \mathrm{~cm}$ and $175 \mathrm{~cm}$ and dry seasons are clearly marked. Relative humidity is low throughout the year and accounts for the heavy rainfall. The climate is reminiscent of the forest zone of Ghana (Dickson and Benneh, 1988). It is typically humid tropical, which is characterized by a relatively warm, rainy, and cool and dry seasons. The annual rainfall pattern is the double peak type with peaks occurring in June and September/October (Dickson and Benneh, 1988). The area is underlain by a large mass of granitoids known as the Cape Coast and Winneba (G1) rock types (Kesse, 1985). These granitoids are related to the later stages of the Eburnean Orogeny, at or after the end of the Birimian deposition. These are well foliated, often magmatic, potash-rich granitoids which come in the form of muscovite biotite granite and granodiorite, porphyroblastic biotitegneisises, aplites and pegmatites (Kesse, 1985). These granitoids are characterised by the presence of many enclaves of schist's and gneisses. They are generally associated with Birimian metasediments and their internal structures are always concordant with those of their host rocks. The Cape Coast granitoid complex is believed to represent a multiphase intrusion consisting of four separate magmatic pulses. It is believed that the last phase is associated with the upper group of Birimian metasediments (Kesse, 1985). The soils encountered at the site are weathering products of the under- 
lying rocks.

\section{METHODOLOGY}

The survey sought to identify and document areas in the walls of the building severely affected by the problem of dampness. This should assist in a detailed investigation later to aid in the recommendation of appropriate methods to address the problem. The investigation consisted of a single case study of the building reported to be experiencing severe dampness problems. Literature reports that in an invasive inspection, more can be learned about damp damage in one inspection than in a hundred more cursory surveys (Burkinshaw and Parrett, 2004). The building was chosen because it had been severely affected by dampness and therefore offered a suitable case for study. The study adopted a holistic approach to dampness investigation involving observation of symptoms in relation to the whole of the building, of the site, and of the information that could be gathered about the locality (Burkinshaw and Parrett,
2004).

Visual investigation, investigation using moisture meters and destructive testing were three out of the four main procedures of dampness investigation that were adopted (Halim et al., 2012; Burkinshaw and Parrett, 2004). The visual investigation stage ensured that the problem was closely inspected and it acted as a preliminary assessment for further investigation (Halim et al., 2012; Burkinshaw and Parrett, 2004). It was conducted through the observation of the surrounding area, checking of the damp zones and physically identifying the causes of the dampness based on the symptoms identified. Furthermore, examinations of the exterior of the building from street level and from higher access (roofing, rain water gutters, etc.) were carried out for any obvious defects. Also the interior parts of the building were examined to determine areas affected by dampness.

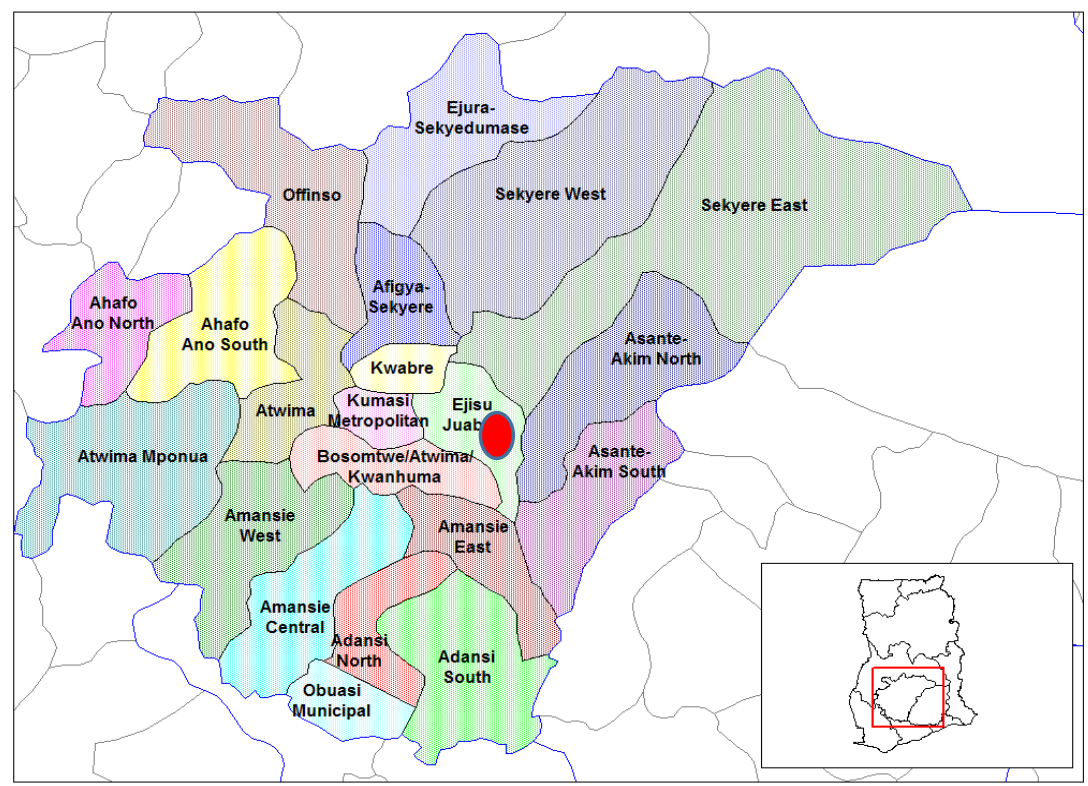

Fig. 1: Location of the study area

Source: www.ghanadistricts.com/home 


\section{Agyekum et al.}

The second stage involved the use of a moisture meter to non-destructively diagnose the areas in the walls susceptible to severe dampness attacks (Halim et al., 2012; Burkinshaw and Parrett, 2004). The non-destructive testing was carried out using the PCE-MMK1 universal moisture meter to identify the problematic areas. The moisture content measurements were taken on walls which showed symptoms such as blistering of paints, staining, mold growth, etc. Grids of $300 \mathrm{~mm} \times 300 \mathrm{~mm}$ were drawn on the surfaces of affected walls and moisture measurements were recorded.

The PCE-MMK1 universal moisture meter was used to measure moisture contents in the sandcrete block walls of the house. This is a multifunctional equipment that can read moisture content, temperature and the relative humidity of the affected walls. Checklists were prepared to record readings. Since all the walls of the four main orientations (southern, northern, eastern and western) had been affected by dampness, grids of $300 \mathrm{~mm} \times 300 \mathrm{~mm}$ were drawn

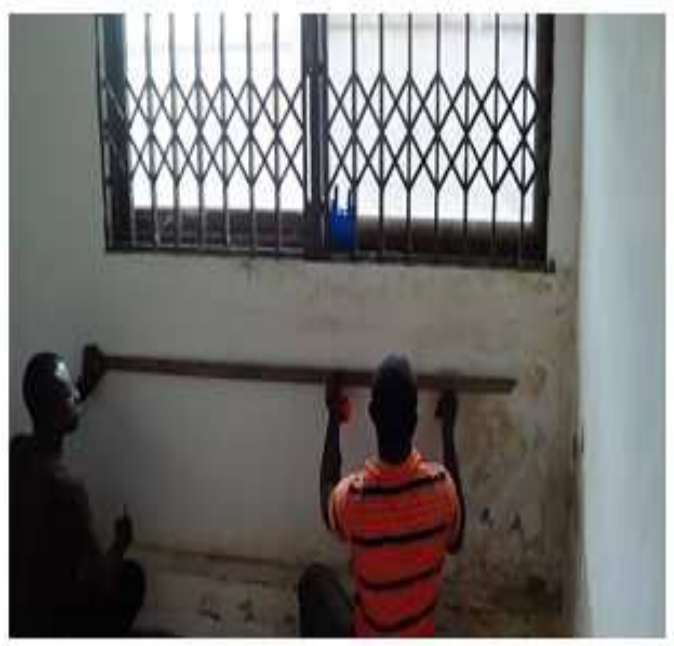

Fig. 2: Marking grid points with light wooden batten for moisture measurements using a tape measure and light wooden batten (Figs. 2 and 3). Damp walls in the southern, northern and eastern orientations extended up to $900 \mathrm{~mm}$ and grids were drawn as shown in Fig. 3. A similar procedure was used for the walls in the western orientation where dampness reached a height of $1200 \mathrm{~mm}$ for the walls of the bedroom and bathrooms respectively.

Both moisture contents and relative humidity readings were recorded. These readings were important in identifying areas within the wall zones where the problem was very severe for further investigation to be undertaken.

For the PCE-MMK1 universal moisture meter maximum moisture content and relative humidity for masonry materials like cement mortar are recorded at $3.0 \%$ and $100 \%$ respectively. For this study, moisture content and relative humidity readings were interpreted as follows (Halim and Halim, 2010):

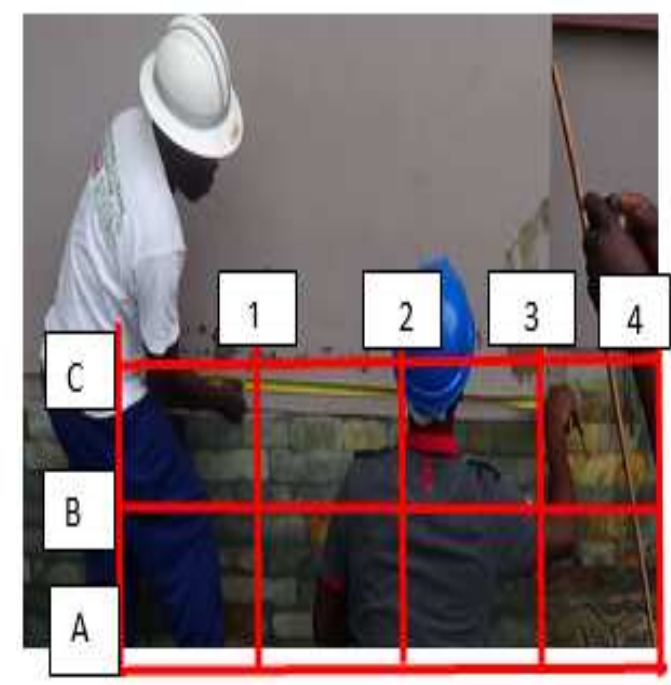

Fig. 3: Tape measure laid against wall 
1. The wall is considered a very wet zone where the moisture contents recorded are greater than $2.8 \%$ and the relative humidity ranges between $22 \% \mathrm{rH}-100 \% \mathrm{rH}$;

2. A moist condition is recorded where the moisture content ranges between $1.5 \%$ $2.8 \%$ and the relative humidity lies between $18 \% \mathrm{rH}-21 \% \mathrm{rH}$; and

3. A dry condition or level of dampness is recorded where the moisture content is less than $1.5 \%$ with relative humidity ranging between $6 \% \mathrm{rH}$ and $18 \% \mathrm{rH}$.

The gridlines were coded using alphabets (for horizontal gridlines) and figures (for vertical grid lines) as shown in Fig. 3.

The third stage which is the destructive testing involved the use of tools such as hammer and chisel to cut pieces of the walls to enable further investigation to be undertaken (Halim et al., 2012; Burkinshaw and Parrett, 2004).

\section{RESULTS AND DISCUSSIONS}

Building details

The building under study is a six bedroom residential apartment located at Kwamo in the Ashanti Region and constructed in 2006. The site slopes gently from the east towards the west. This slope may have a bearing on the flow of storm water against one of the walls of the building and as such may contribute to the dampness if the land is not properly drained. The soil consists predominantly of loose to dense sand with various percentages of clay, silt and some gravel. The building orientation is such that the back elevation faces north, front elevation faces south, right elevation faces east and left elevation faces west. The mode of construction is artisanal, where itinerant workers are employed, most at times without professional supervision, the type very common in Ghana. Walls are monolithic (sandcrete blocks) and the internal and external walls are constructed of the same sizes and compositions. The external and internal walls are rendered and plastered respectively. The foundation of the building is the concrete strip type with no damp proof course provided, though the occurrence of dampness is not solely due to the use of DPCs. The roof is hipped with aluminium sheets on wooden structural systems. The floor is made of concrete with a tile finish. The windows in the kitchen and washrooms are made of glass louvre blades in hard wooden frames and those in the living and bedrooms are made of sliding windows in aluminium frames. Hardwood timber skirting boards are used at the bases of the internal walls. The entire compound is paved in blocks with grass lawns around the building. The survey was undertaken between October 2013 and November 2013.

\section{Results from site inspection}

The site inspection carried out revealed that all the bedrooms were installed with air conditioners. On the eastern orientation, where the master bedroom was located, water from the air condition dripped directly against the base of the wall and that area appeared to be very wet (Fig. 6). Furthermore the upstand upon which the air-condition stands (Fig. 6), may act as a barrier to surface rain water, thus retaining storm water and preventing it from flowing away, thereby enabling the wall to soak it.

Symptoms of dampness were identified on the external walls of all the four orientations and were very severe in the walls of the bathrooms and the adjoining bedrooms. Blistering of paint, flaking of plaster and surface efflorescence were evident on most of the external and internal wall surfaces. Dampness was evident in all the walls but was very pronounced, rising to a maximum height of $1200 \mathrm{~mm}$ in the walls in the western orientation (left elevation, Fig. 7).

Inside the building, the walls of all the six bedrooms showed signs of dampness. The partition walls between the bedrooms and washrooms showed serious symptoms of dampness. Bedroom 1 (Fig. 5) was severely identified with this problem. Blistering of paint, flaking of 


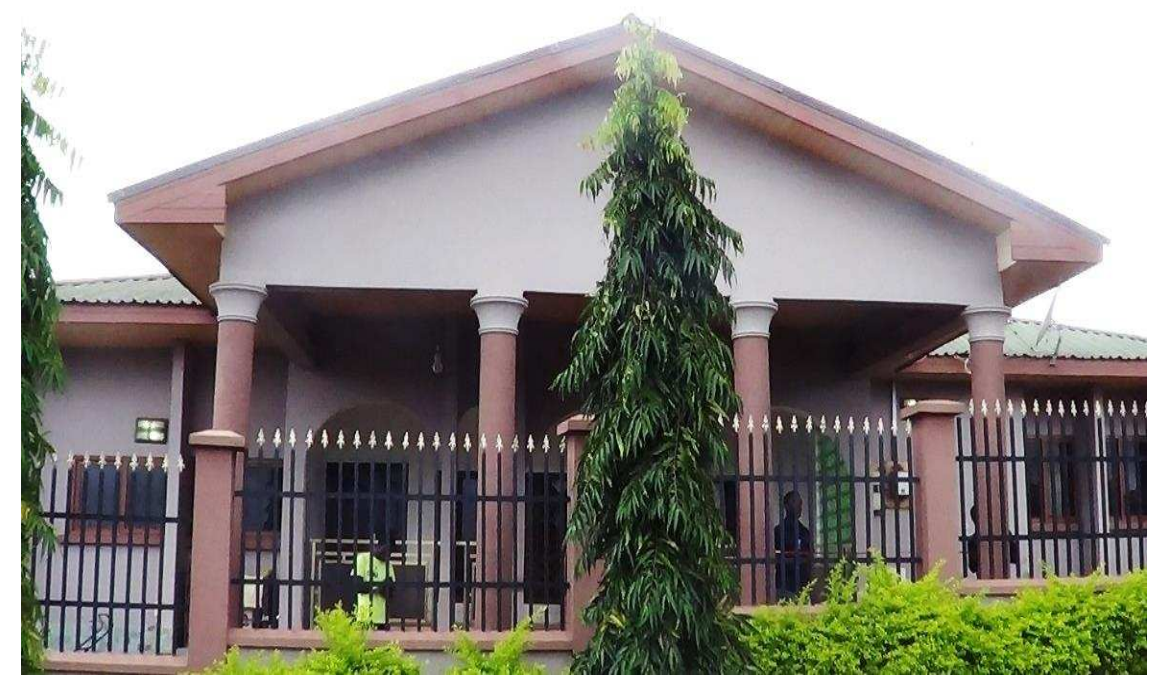

Fig. 4: Front part of the building under study

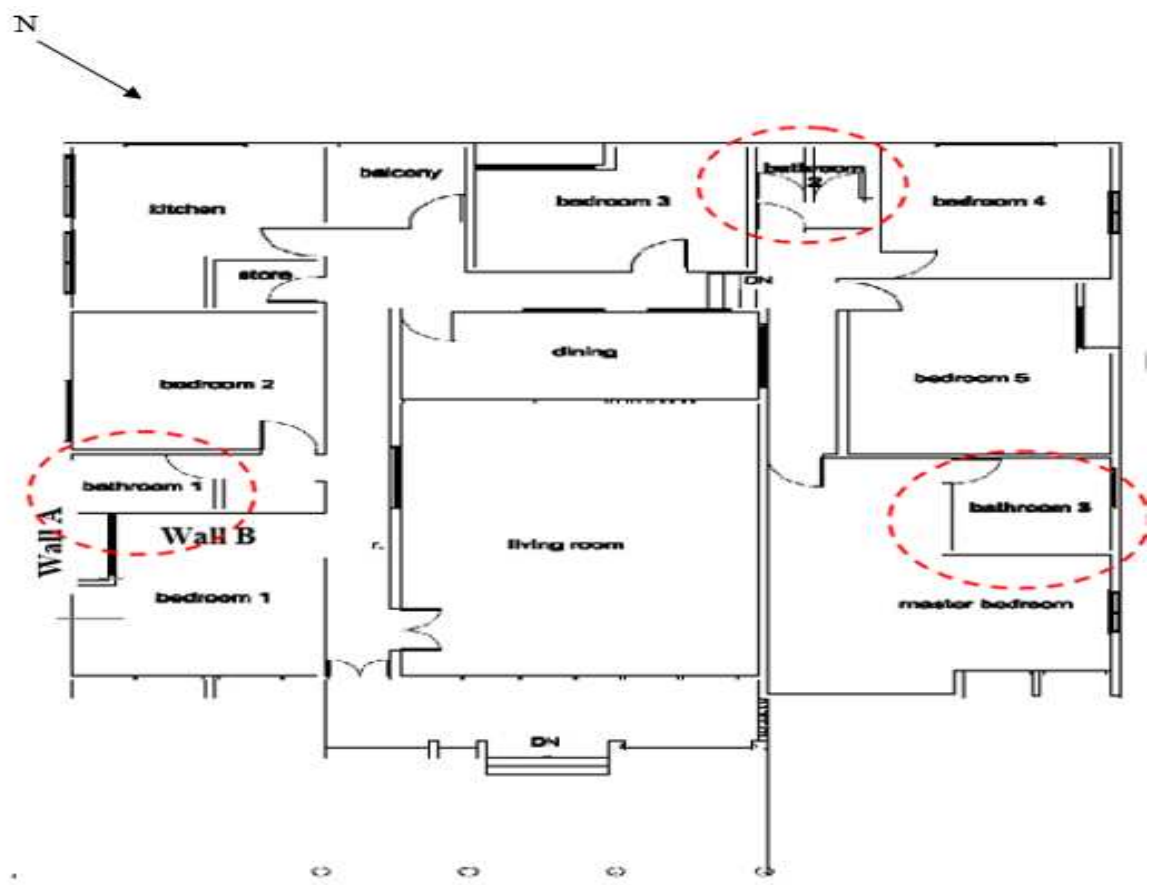

Fig. 5: Ground floor plan of building under investigation (not to scale) 


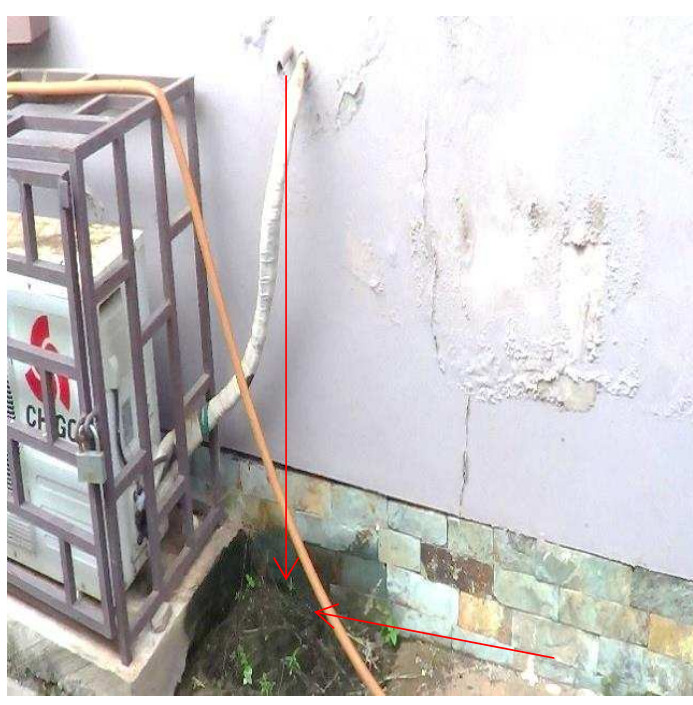

Fig. 6: Water from air condition dripped against the base of wall

plaster and surface discolorations were identified on the internal walls of most of the bedrooms.

Salt deposits (arrowed part) (Fig. 8) were seen on the partition wall (B) between the bathroom and bedroom 1 . The stains on the wall (A) was only in the room and no signs or symptoms were identified behind the walls externally. This could be a clear case of condensation because the room was being used as a store room instead of a bedroom, with the windows closed always. This made it difficult for the room to be ventilated. According to Noy and Douglas (2005), plinths when applied to solid walls will bridge damp proof courses if any and this will cause rising damp to penetrate through the wall plaster and skirting. If this is the case then there could be combinations of different sources of dampness in this room. Similar situations occurred internally in the other bedrooms.

Moisture content distribution and detailed analysis

The distribution of moisture contents along and

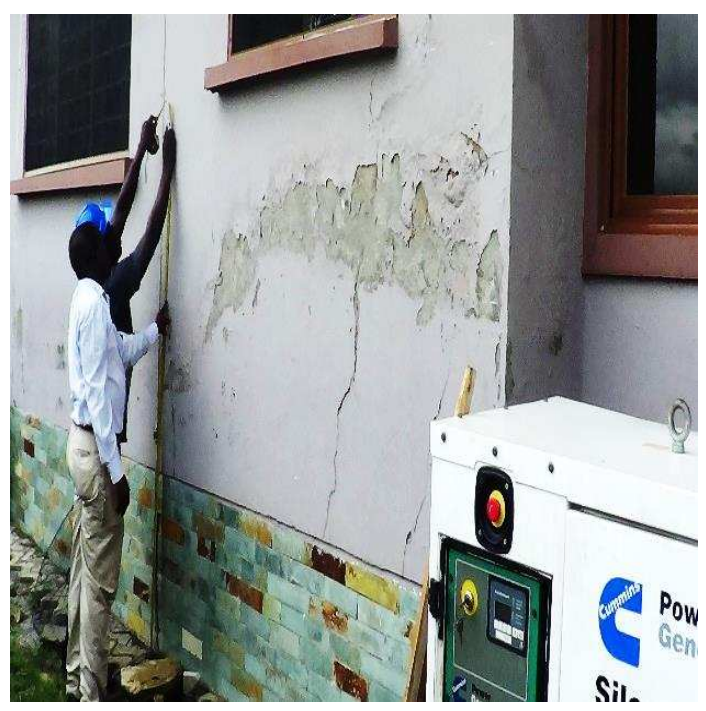

Fig. 7: Western orientation-Dampness measured up to $1.2 \mathrm{~m}$ on external walls of bathroom

across the faces of the severely affected walls are shown in Fig. 9 to 15.

Fig. 9 shows relative humidity readings recorded by the moisture meter in the walls of bedroom 1 (Fig. 8). All the readings fell within the ranges of $70 \%$ and above which indicated high levels of dampness (Halim and Halim, 2010).

Results from the moisture content measurements on the internal wall (A) of bedroom 1 (Fig. 10) showed that dampness was dominant in the part of the wall towards the partition wall (B) between bedroom 1 and Bathroom 1. The damp zones were identified between gridlines A3-A7 through to E3-E7 (circled in red). On the other internal wall of bedroom 1 (B) (Fig. 11), the damp zones were identified between gridlines A1-A5 through to E1-E5.

Fig. 12 and 13 show the distribution of moisture externally on the walls oriented in the southern direction. From the moisture contents recorded, the damp zones were identified to fall 


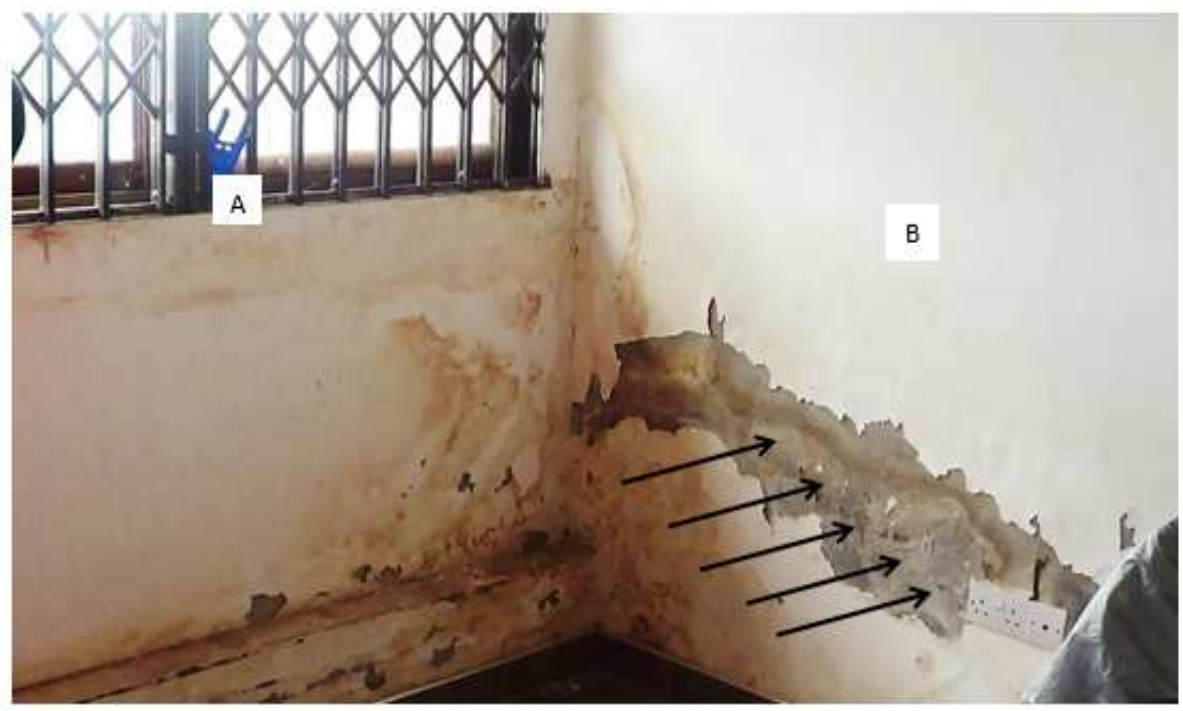

Fig. 8: Stains on internal walls of bedroom 1 (A) and partition of bathroom and bedroom (B)

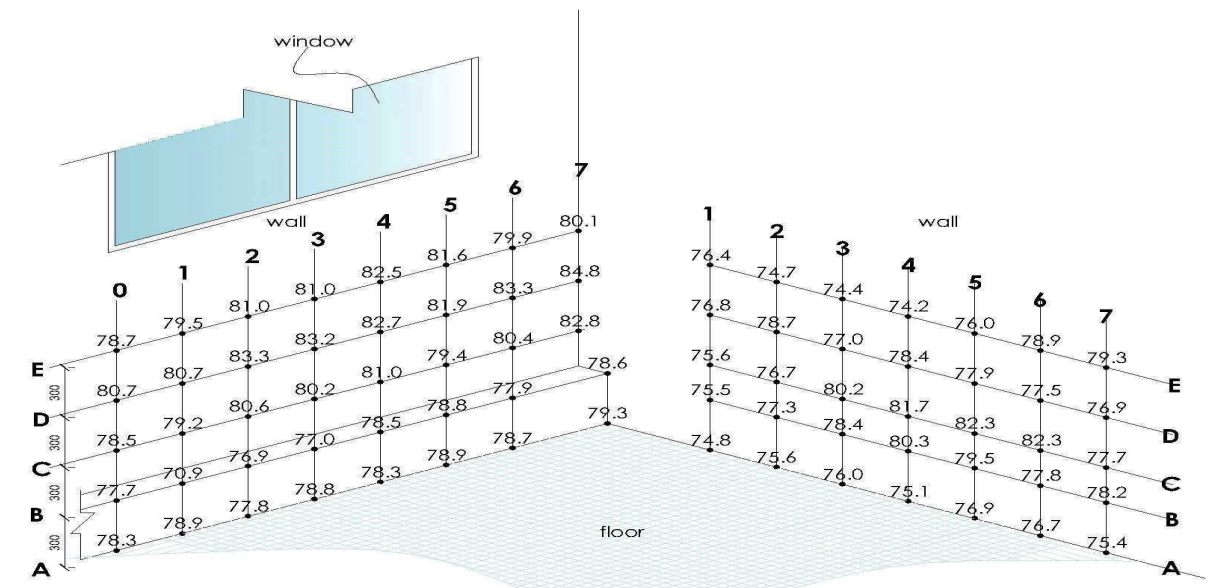

Fig. 9: Relative humidity readings from two internal walls of bedroom 1

within gridlines A0-A1 through to $\mathrm{C} 0-\mathrm{C} 1$. Furthermore, gridline A5 - C5 were identified as part of the damp zones.

Though there appeared to be minor symptoms of dampness such as peeling off of paints and cracks on the walls in the northern direction, readings taken from the moisture meter indicated that dampness was not severe. These symptoms could possibly be due to problems associated with poor workmanship. 


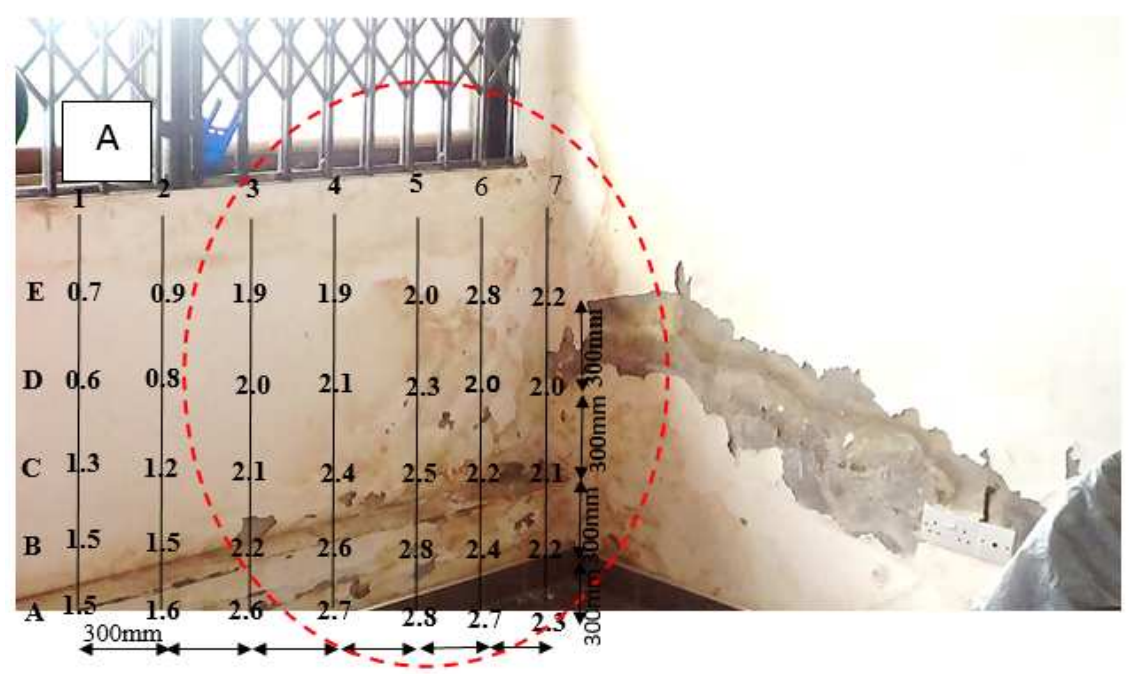

Fig.10: Moisture content readings from internal wall (A) of bedroom 1

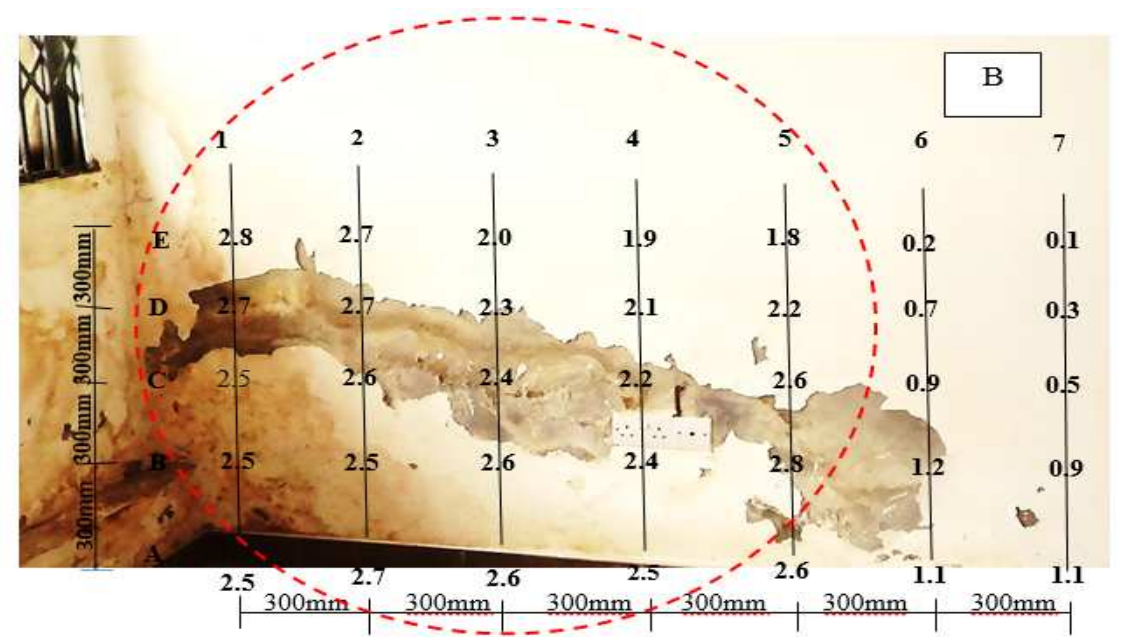

Fig. 11: Moisture content readings of internal wall (B) of bedroom 1

Destructive testing

A further survey of the building revealed problems of plumbing leakages in all the bathrooms. Most of the internal damp problems stemmed from the shower cubicle leaks. These leakages were so pronounced that it had affected the adjoining walls of all the bedrooms. Leaks can cause problems both inside and outside of a building (Burkinshaw, 2009). 


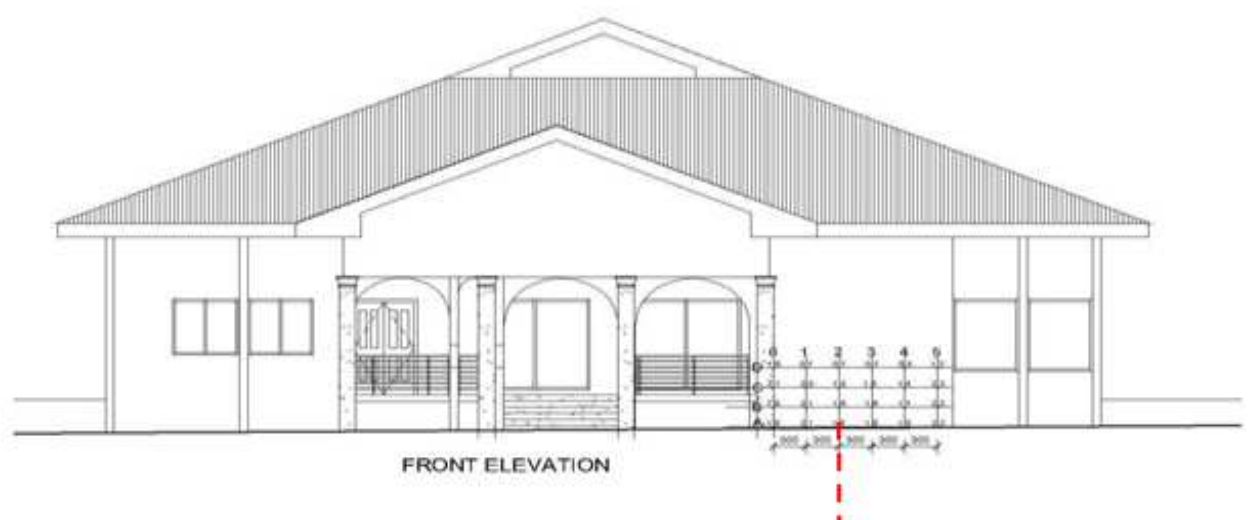

Fig. 12 Moisture meter readings on walls of Southern orientation (front elevation)

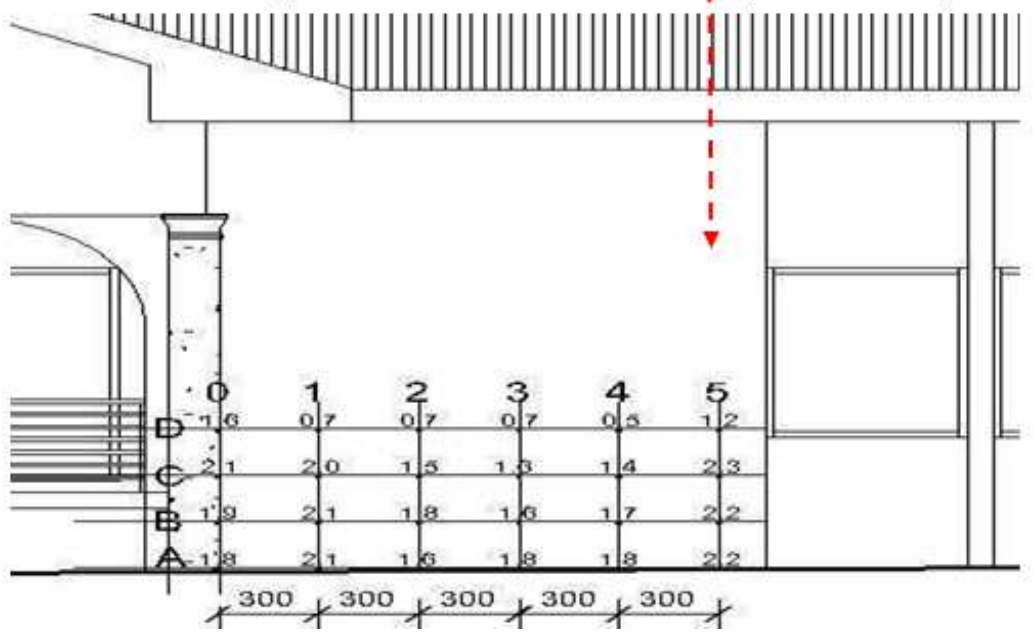

Fig. 13: Moisture contents measured on walls of southern orientation (enlarged)

Bathrooms 1 and 2 (Fig. 5 marked in red) had similar problems. Steady drips in concealed voids from around the spindles of the traditional stop valves amounted to substantial water escapes over prolonged periods and these penetrated the walls. In Fig. 16, drips of water is seen as a plumber tries to solve the problem.

Another problem that was seen to be peculiar to bathrooms 1 and 2 was the leakage resulting from shower trays. Trays should be designed with a sloping perimeter kerb and better trays available always have upstands (Burkinshaw, 2009). Fig. 17 shows that the trays were very shallow. The glass panels were not enclosed on all three sides to create a shower cubicle. This caused water to splash out of the tray onto the floor and this was confirmed by the owner who said the floors became flooded any time someone took a bath. This situation is very dangerous because anytime this happened, the water that fell outside the tray could find its way through any gaps or flaws in the tile grouting (Burkinshaw, 2009). This is the situation seen 


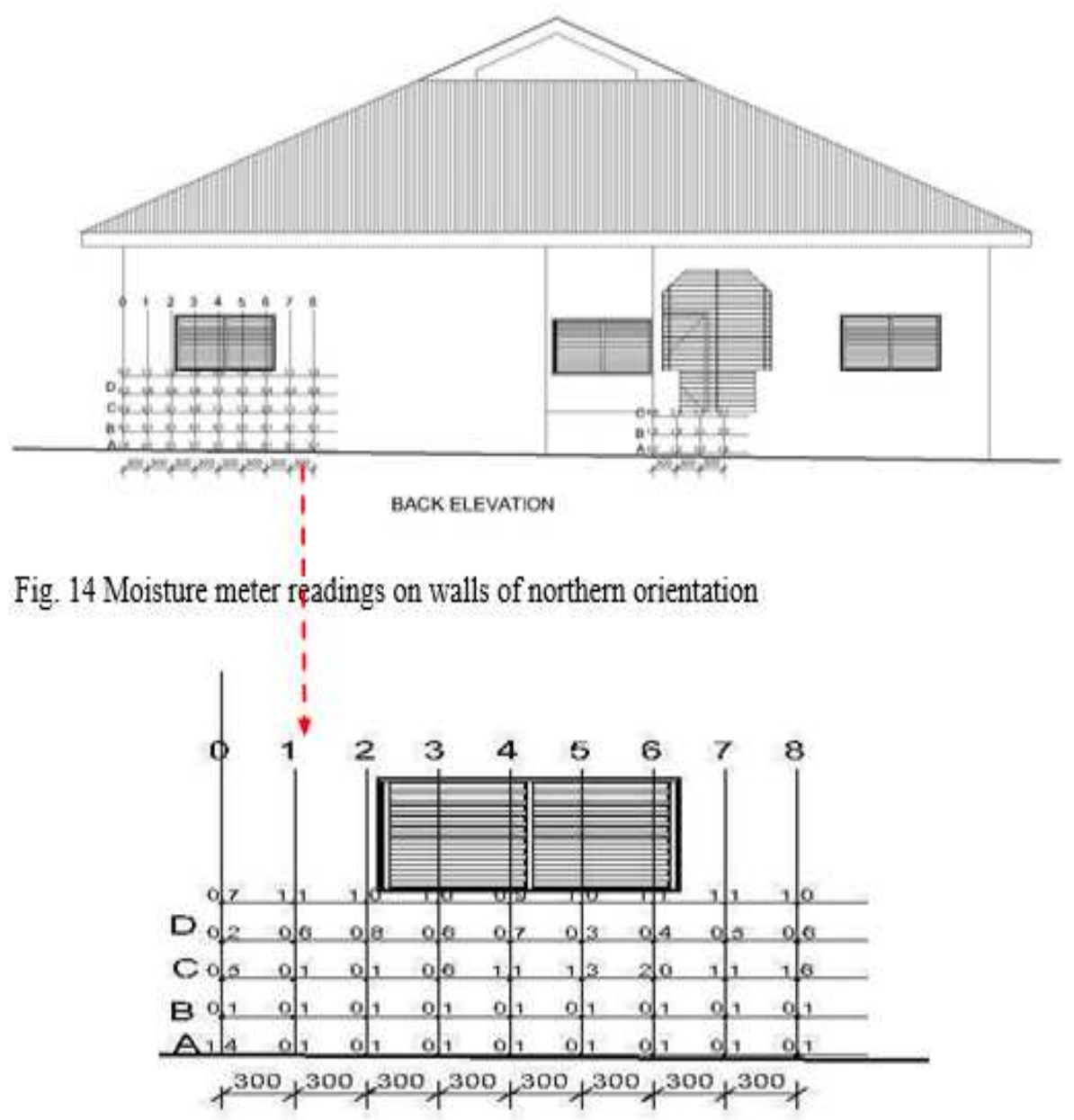

Fig. 15 Moisture contents measured on walls of northern orientation (enlarged)

in Fig. 17 and this resulted in the leaked water penetrating the porous block masonries of adjoining walls (Fig. 8). The support for trays need to be level and as stable and rigid as possible (Burkinshaw, 2009). If there are no upstands for trays, failure of the edge seals will mean that shower water can penetrate through the edge of the tray down and stay underneath to cause damp damage. Poor seals can result in wetting and deterioration of the wall plasters as seen in Fig. 8.
The trays offered no opportunities to access the traps and waste connections underneath. Therefore, it became very difficult to see early warning signs of developing damp problems, especially from very small but persistent drips, and these can contribute to the wetting of the porous block walls. Such situations can also create conditions of high air humidity under the tray (Burkinshaw, 2009). A destructive test conducted on the trays revealed poor fitting of the flexible connector that linked the tray to the 


\section{Agyekum et al.}

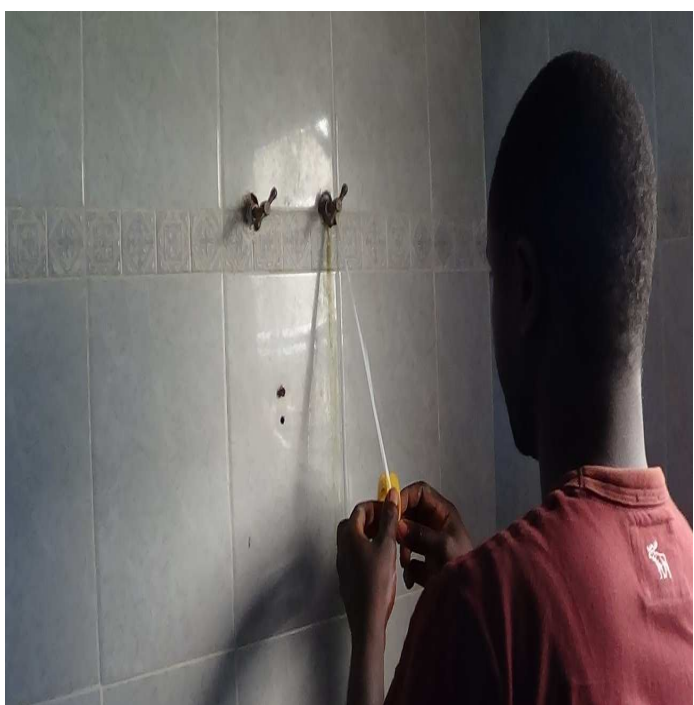

Fig. 16: Inspection of stop valves by a plumber

waste pipes. Because this connector was faulty, water that tracked under the tray from bathing stayed on the solid floor and soaked the porous block walls.

The bathroom in the master bedroom (Fig. 5) suffered similar problems as seen in the first two bathrooms.

Bath ledges are possible leak zones (Burkinshaw, 2009). The bath tub in Fig. 20 had a peculiar problem. Instead of the water travelling downwards from the tiles on the vertical walls to the bath tub's edge and then into the bath, water settled on the horizontal surface and seeped through any tiling flaws in the edge seals. This is what happened in bathroom 3 and resulted in the condition on the external wall located in the eastern orientation (Fig. 21). Fig. 24 is a blown up detail drawing of the bathtub showing the tub abutting the wall tiles.

\section{Diagnosis}

According to Burkinshaw and Parret (2004),

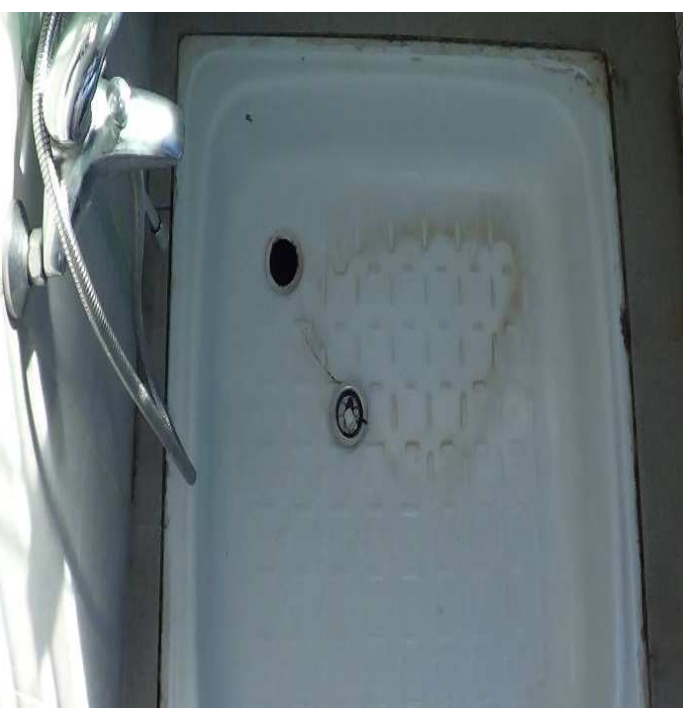

Fig. 17: Shower tray fixed in bathroom 1

when uniformly high readings are obtained in a wall the surveyor should take the investigation further there and then undertake a closer visual observation inside and outside the building in that particular zone.

The detailed analysis of the damp walls in this study revealed that most of the internal damp problems stemmed from plumbing leakages resulting from the shower cubicle leaks (shower trays and bath tub). These leakages affected adjacent walls and were mostly associated with the peeling off of plasters and paints and blistering of mortar. Stains in the form of arches were also seen to be associated with these leakages in the affected walls.

The internal walls of bedroom 1 showed the most severe case of dampness and symptoms identified depicted combinations of several sources of dampness. Symptoms such as surface efflorescence, flaking of plaster and blistering of paints are associated with rising dampness. However, plumbing leakages result- 
Holistic approach to dampness surveying...
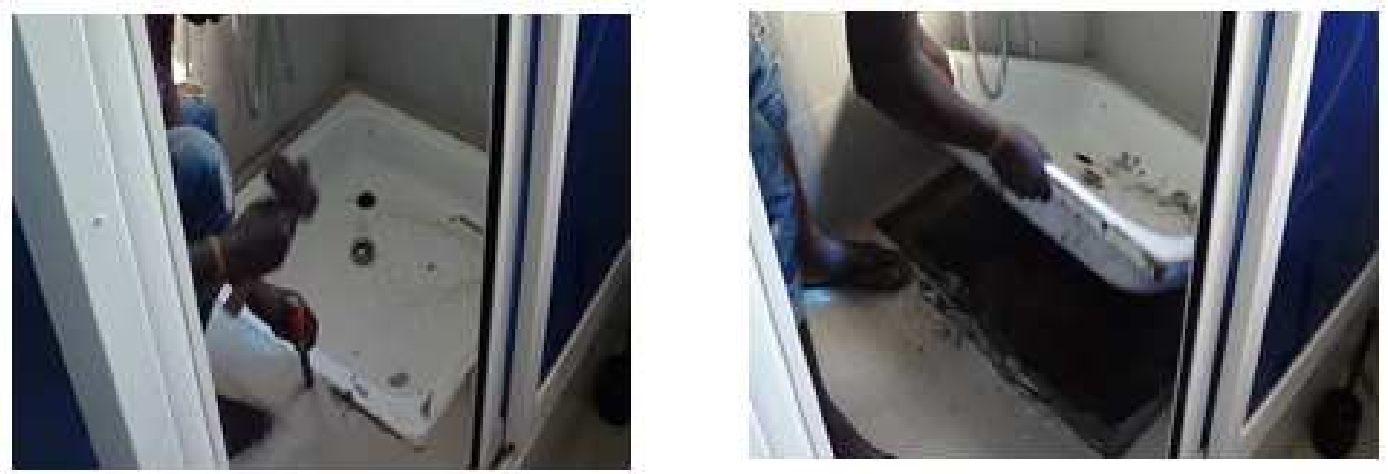

Fig. 18: Shower tray being removed to check the situation underneath
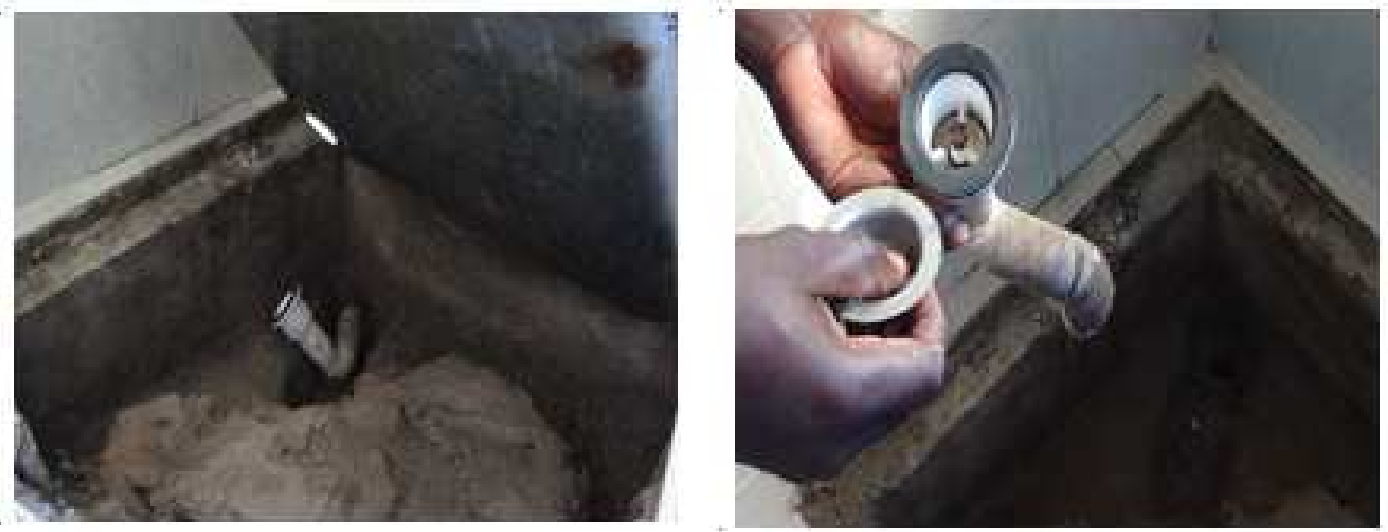

Fig. 19: Faulty flexible connector being examined

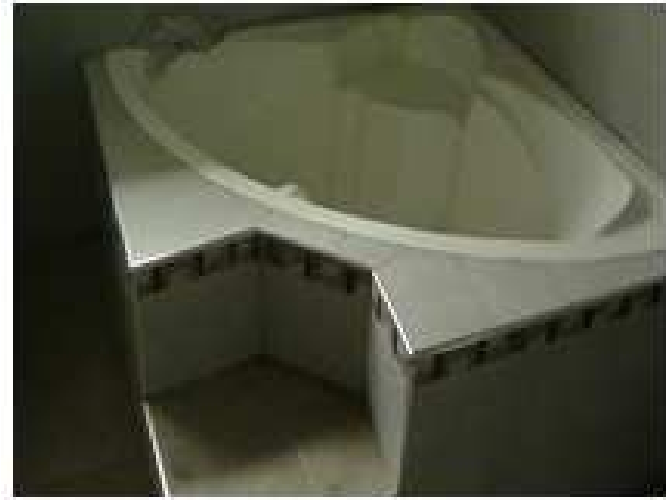

Fig. 20: Bath tub in master bedroom

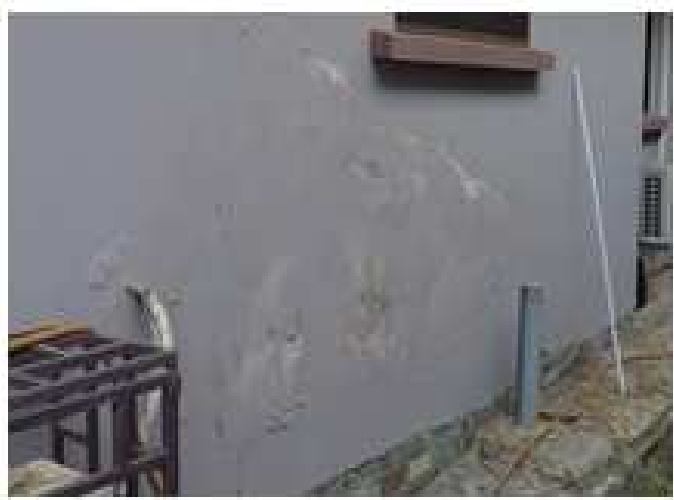

Fig. 21: Dampness on external wall of master bathroom

Journal of Science and Technology ㄷ KNUST April 2014 

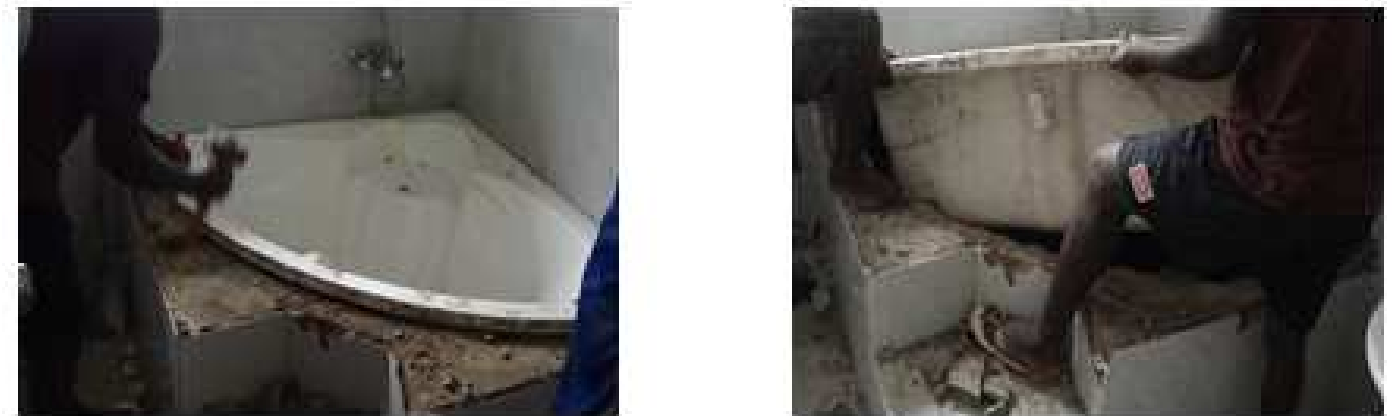

Fig. 22: Tiled walls of the bath tub had to be hammered to pieces to enable the defective bath to be removed
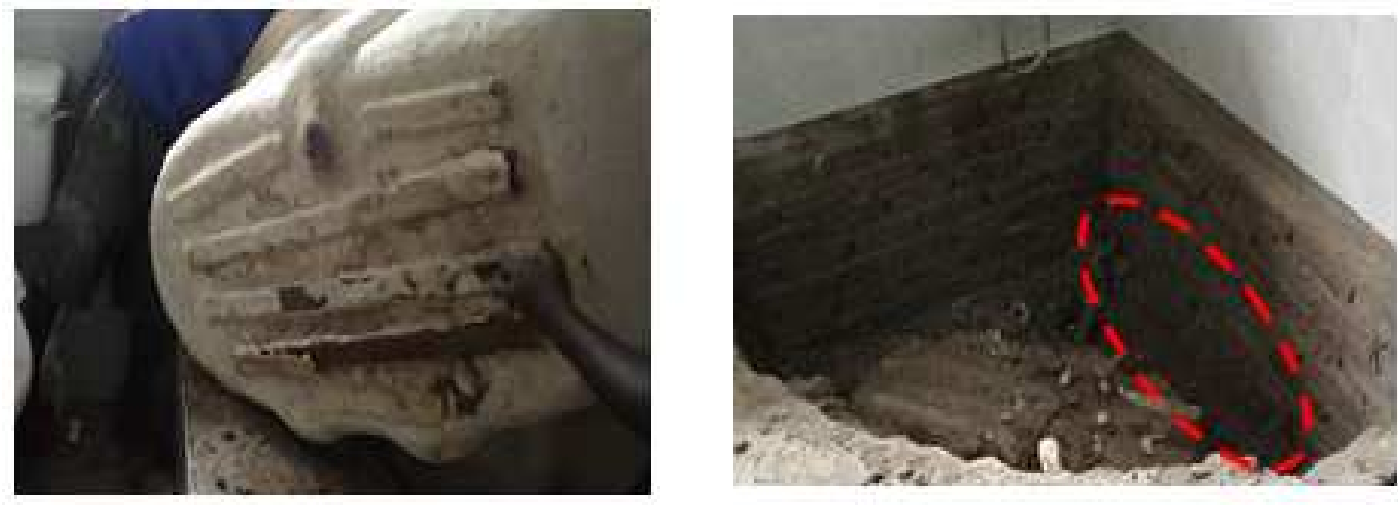

Fig. 23: Conditions at the base of the bath tub after it was removed

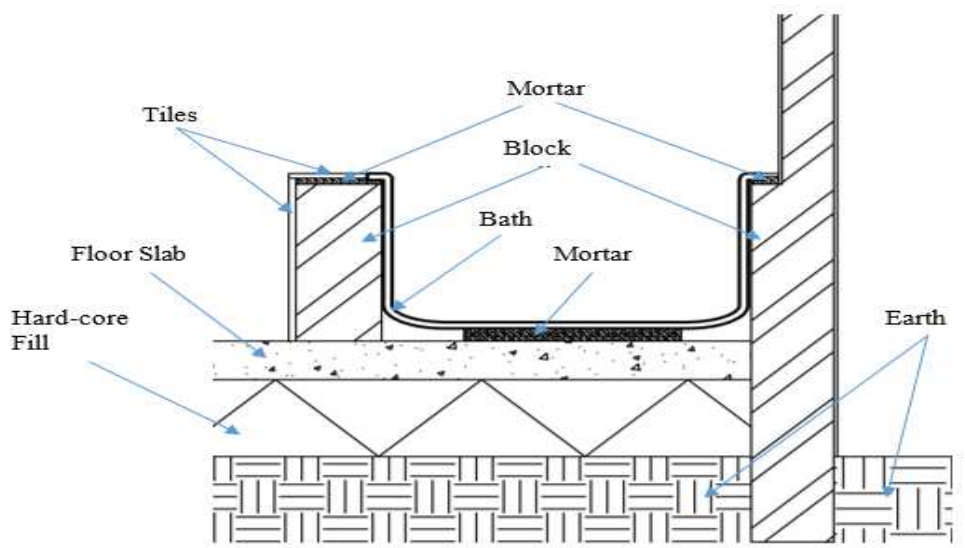

Fig. 24: Detailed drawing of bathtub showing tub abutting wall tiles 
ting from the faulty trays and bath tubs also contributed to the penetration of water in the walls of the building. This caused the damp in those walls to rise above $1.5 \mathrm{~m}$.

\section{Prognosis}

Once the diagnosed plumbing leakages in the washroom areas are fixed, the wet walls will dry out and these areas will be monitored.

Improving the ventilation in bedroom 1 should improve the situation of dampness in this room. Fixing the flexible tubes that link the shower trays to the waste pipes and re-fixing the shower cubicles should reduce the problem of leakages in the washrooms and adjoining walls of bedrooms.

The problem of dampness on the external wall of the kitchen was due to rain water as the building owner reported that any time there was severe rainfall, water found its way through the windows in that direction to the kitchen. This problem could not be attributed to orientation because the building was oriented in the north south direction, the type typical for buildings sited in the tropics. Providing an appropriate overhang to check the angle with which water from rainfall directly hits the wall should minimize this problem in the kitchen. Waste water drifting from the air condition to the bases of the external walls if checked would reduce the water rise in these areas. Roof coverings and other related items were in good conditions so there were no contributory factors from leakages from the roofs.

\section{CONCLUSION}

The investigation revealed that there are combinations of several sources of dampness in the building. These included plumbing leakages among others. The site inspection revealed that dampness in the walls of the building was associated with symptoms such as cracks in walls, blistering of paint, flaking of plaster, surface efflorescence and stains on walls. Most of the symptoms identified were closely related to rising dampness as previous studies have attributed such symptoms to rising damp. The non-destructive tests conducted with the PCEMMK1 universal moisture meter identified the dampness to be pronounced in both the external and internal walls oriented in the western direction. The plumbing leakages identified in the bathrooms located within this orientation could have contributed to the severity of the dampness. Furthermore, dampness was pronounced in the internal walls of bedroom 1 (located in the western orientation) than the other bedrooms. All the destructive tests conducted in the bathrooms located within the building revealed that dampness in most of the internal walls were probably due to plumbing leakages. A summary of the conclusion drawn from this study includes:

- There appeared to be a rise in the water level along the walls of the building. However, a sharp increase in the rise in the form of an arch was seen in the walls affected by plumbing leakages;

- There was no access for inspection under the shower trays and bath tub. The tiled walls of the trays and bath tub had to be hammered to pieces to enable the defective trays and bath tubs to be removed;

- There were no access for maintenance of the trays and bath tubs;

- The shower trays and faulty cubicles made it easier for water to drip outside the tray and this possibly penetrated the tiles;

- The trays had no upstands and relied on tiled sealings a possible route for water penetration; and

- The site slopes gently from the east towards the west, where dampness was pronounced in the walls, both internally and externally. This slope of the terrain may have a bearing on the flow of storm water towards these walls and as such may con- 
tribute to the dampness if the land is not properly drained.

Once plumbing leakages have been ruled out, it is recommended that a more detailed laboratory diagnosis be conducted on the walls in other areas of the building which showed symptoms closely related to rising dampness.

\section{REFERENCES}

Agyekum, K., Ayarkwa, J., Koranteng, C. and Adinyira, E. (2013). "Preliminary assessment of dampness in walls of residential buildings in four climatic zones in Ghana". Journal of Sustainable Development, 6 (9): 51-61.

Ahmad, A. G. and Abdul Rahman, H. F. (2010). Treatment of Salt Attack and Rising Damp in Heritage Buildings in Penang. Malaysia. Journal of Construction in Developing Countries, 15 (1): 93-112

Burkinshaw, R. (2009). Remedying Damp. Coventry, UK: Rics-Royal Institution of Chartered Surveyors Books.

Burkinshaw, R., and Parrett, M. (2004). Diagnosing damp. RICS BOOKS, Coventry.

Briffett, C. (1994). Building Maintenance Technology in Tropical ClimatesInvestigating dampness problem in buildings. Singapore University Press, Singapore.

Dickson, K. B. and Benneh, G. (1988). A New Geography of Ghana. Pearson Educational Limited, Essex, England.

Ghana Districts-A repository of all districts in the Republic of Ghana. Available www.ghanadistricts.com/home, accessed 4/07/2012
Halim, A. A. and Halim, A. Z. (2010). An analysis of Dampness Study on Heritage Buildings: A Case Study Ipoh Old Post Office Building and Suluh Budiman Building. UPSI, Perak, Malaysia. Journal of Sustainable Development, 3: 171-182

Halim, A. A., Harun, S. N. and Hamid, Y. (2012). Diagnosis of dampness in conservation of historic buildings. Journal Design + Built, 5 (1): 1-14.

Hetreed, J. (2008). The damp House: A Guide to the causes and Treatment of Dampness. Crowood Press, UK.

Hollis, M. (2002). Pocket Surveying Buildings. RB-RICS Books, Coventry.

Kesse, G. O. (1985). "The Mineral and Rock Resources of Ghana”. Balkema, A. A. Rotterdam, the Netherlands, 610 .

Mbachu, J. I. C. (1999). "Dampness in Residential Building Walls: A case study of Angwan Rimi Ward of Jos Metropolis". Journal of Environmental Science, 3 (1): 80-84.

Noy, A. E. and Douglas, J. (2005). Building Surveys and Reports. Third Edition, Blackwell Publishing, UK.

Oxley, R. (2003). Survey and Repair of Traditional Buildings, A Sustainable Approach, Great Britain: Bath Press.

Yilmaz, U. S., Dereli, M., Korur, S. and Korkmaz, Z. (2010). "Water based damages on building faces and solution proposals". BALWOIS 2010-Ohrid, Republic of Macedonia; 25-29 May 2010, 1-7. 